\title{
A Leverage Theory of Reputation Building with Co-branding: Complementarity in Reputation Building*
}

\author{
Jay Pil Choi ${ }^{\dagger}$ and Doh-Shin Jeon ${ }^{\ddagger}$
}

March 5, 2007

\begin{abstract}
We present a leverage theory of reputation building with co-branding. We show that under certain conditions, co-branding that links unknown firms in a new sector with established firms in a mature sector allows the unknown firms to signal a high product quality and establish their own reputation. We compare this situation with a benchmark in which both sectors are new and firms signal their quality only with prices. We investigate how this comparison is affected by the nature of the technology linking the two sectors and a cross-sector inference problem that consumers might face in identifying the true cause of product failure. We find that co-branding facilitates the process in which a firm in the new sector to signal its product quality only if the co-branding sectors produce complementary inputs and consumers face a cross-sector inference problem. We apply our insight to economics of superstars, multinational firms and co-authorship.

Key Words: Leverage, Co-branding, Complementarity in Reputation Building, Inference Problem.
\end{abstract}

JEL Codes: D82, L15, M31

${ }^{*}$ We thank seminar participants at Hong Kong University of Science and Technology, Korea University, National University of Singapore, Seoul National University, Universitat Pompeu Fabra, Yonsei University. We also thank Juanjo Ganuza, Andreu Mas-Colell, Jae Nahm and Julian Wright for comments. Jeon gratefully acknowledges financial support from the Spanish Ministry of Science and Technology under BEC2003-00412 and the Ramon y Cajal grant.

${ }^{\dagger}$ Michigan State University

$\ddagger$ Universitat Pompeu Fabra and CREA 


\section{Introduction}

This paper considers an adverse selection model in which we analyze how the reputation of one firm can be transferred to another that sells a different product. More specifically, we consider a situation that there are two sectors in an economy. One sector is mature in that firms in that sector have already established their reputation and consumers are informed about the quality of their products. The other sector is new and hence firms in that sector have yet to establish their reputation. The question we ask in this context is whether there exists a mechanism to leverage reputation from the firms in the mature sector to the ones in the new sector.

In our model, the mechanism through which such leveraging of reputation takes place is co-branding. We show that there exist conditions under which being associated with a good brand in the mature sector allows a firm in the new sector to signal a high quality product and establish their own reputation. We compare this situation with a benchmark in which both sectors are new. In both cases, reputation building is modelled in terms of signaling. In the benchmark case where both sectors are new, we investigate the condition under which there exists a separating equilibrium with prices being the instrument of signaling. In the former case where one sector is mature, we study the condition to have a separating equilibrium with co-branding. We say that there exists complementarity in reputation building if the condition for the existence of a separating equilibrium is more relaxed with co-branding. We investigate how this comparison is affected by the nature of the technology linking the two sectors (i.e. whether components produced by both sectors are complementary or not) and a cross-sector inference problem that consumers might face in identifying the true cause of product failure. We find that co-branding facilitates the process in which a firm in the new sector to signal its product quality if and only if the co-branding sectors produce complementary inputs and consumers face a cross-sector inference problem. Compared to the benchmark case in which both sectors are new and hence no firm has yet established its reputation, the fact that the economy has one mature sector helps firms in the new sector to build their reputation. Thus, complementarity in technological relationship between the two sectors induces complementarity in reputation building only if the cross-sector inference problem exists. We apply our insight to the role of movie stars in the motion picture industries, co-branding of global brands by multinational firms and local brands in brand transitions, and co-authorship between established scholars and young scholars.

Co-branding is an extensively used marketing strategy that is especially popular in 
introducing new consumer products. ${ }^{1}$ It is typically defined as "pairing of two or more branded products (constituent brands) to form a separate and unique product (composite brand)." ${ }^{2}$ The marketing literature points out that co-branding plays a key role in changing consumers' perception that the two constituent products will be regarded as being similar quality. Thus, linking with a well-known brand through co-branding can be a particularly effective strategy for an unknown brand in increasing assimilation in the eyes of consumers (Abratt ad Motlana, 2002). Rao, Qu, and Ruekert (1999), for instance, suggest that when an unknown brand cannot effectively signal its high quality, co-branding with a well-known brand of high quality can be an effective way to enter a new market. The marketing literature, however, does not model the mechanism through which the reputation of one brand can be leveraged to build reputation of another firm's brand. They rely either on case studies or experimental tests of hypothesis they posit without any rigorous micro-foundation. Our paper complements the marketing literature by providing a theoretical model that analyzes the mechanism through which the leverage of reputation takes place.

Our paper is closely related to Tadelis (1999) and Cabral (2000). Tadelis studies name trade in an adverse selection framework with overlapping generations of firms. ${ }^{3}$ Cabral applies Tadelis' framework to the issue of brand extension. ${ }^{4,5}$ We extend Tadelis' framework to multiple sectors and study how firms with established names (or brands) in one sector may affect the ability of firms in the other sector to build their own reputation. In particular, we find that complementarity in reputation building is related to complementarity in underlying technology and consumers' inference problems concerning the cause of failure. Our focus thus is on name trading between contemporaneous firms in different sectors, instead of name trading between different generations of firms within the same

\footnotetext{
${ }^{1}$ Simonin and Ruth (1998) report that co-branding activities broadly defined have increased with an annual growth rate of $40 \%$ in the US.

${ }^{2}$ Washburn, Till and Priluck (2000), p. 591.

${ }^{3}$ The first paper on name trades is Kreps (1990) in a moral hazard setting with repeated games.

${ }^{4}$ Choi (1998) studies brand extension in a model of infinite horizon in which a firm can launch a new product every period. An equilibrium in which the firm extends its brand only to products of high quality is sustained by the threat of a breakdown of trust in case a low quality product is sold under the same brand.

${ }^{5}$ Thal (2007) studies brand extension through licensing in an adverse selection framework similar to Cabral (2000). In her model, there are two firms: an incumbent who produces an old product under a brand name and an innovator who launches a new product. The incumbent decides whether to license its brand to the innovator. In contrast, in Cabral (2000), both the old and the new products are produced by the incumbent. Both papers, however, assume that prices are equal to consumers' willingness to pay whereas we allow that prices are used as a signaling device.
} 
sector as in Tadelis (1999). Another important distinction is that Tadelis and Cabral abstract from the possibility of signaling through price by assuming that prices are equal to the consumers' willingness to pay. In contrast, we allow for the possibility of signaling through price in our benchmark and compare it to signaling via co-branding.

The special case of single component products in our model is similar to Bagwell and Staiger (1989) who study export subsidy as a strategic trade policy to overcome information barrier to entry. Major differences are that we study matches among firms producing complementary inputs and name trades between different sectors. In addition, their model assumes that once a consumer is matched to a firm, the relationship is maintained for both periods while the relationship is short-lived in our model. This difference arises since we need to entertain the possibility that firms change their partners based on the newly revealed information about the product outcomes realized in the first period, which they do not need to consider.

Bar-Isaac (forthcoming) develops a theory of reputation in teams to explain organizational design of many professional service providers such as law firms, consulting firms, and medical practices where reputation both at the level of the firm and the individual are crucial. He shows how a partnership structure where a senior works with a junior in tandem provides proper incentives for both senior and junior to work hard: the junior's incentives arise from a concern for her own reputation whereas the senior's incentives arise from a concern for the reputation of her firm which she plans to sell out to the junior. His model employs a joint production technology that is similar to ours in the following sense: individual outputs of a senior and a junior cannot be observed and only combined output of a team of senior and junior is observable. This non-observability of individual contribution in joint production is crucial to his main results and is akin to our assumption that consumers cannot infer the true cause of failure when the final product fails to perform. The incentive problem in his paper is mainly of moral hazard while we are mainly concerned with adverse selection problem. As such, Bar-Isaac's and our papers complement each other.

Our paper is also related to the literature on the economics of superstars (Rosen 1981 and MacDonald 1988), and in particular to Kremer (1993) who studies how the return to talent is affected by technological complementarity and matching. Kremer, however, studies a situation in which agents's types (skill) are common knowledge while our focus is on complementarity in reputation building with the types of firms at least in one sector being imperfect information to consumers. We identify a premium to established names (or superstars) accruing from the ability to allow other complementary inputs to signal 
their quality through matching.

In Section 2, we present the basic model of adverse selection with complementary components. To highlight the importance of technological complementarity, in section 3 we study the case of single component product as a benchmark. We compare two potential instruments for establishing reputation: signaling with prices and signaling with name trades. We find that conditions under which a signaling equilibrium exits are identical in both cases. This result suggests that there is no complementarity in reputation building in the absence of technological complementarity between name traders. What matters for signaling is each type's gain from building reputation (i.e. from being recognized as a high type in our model). Since the gain does not depend on the mode of signaling, the condition to have a separating equilibrium is invariant to the mode of signaling.

Section 4 studies the case of complementary components. In order to investigate the possibility that the reputation of firms in one component sector can be leveraged to build reputation of other firms in the complementary sector, we consider two scenarios. In the first scenario, both sectors are new and firms in neither sector established reputation (i.e. no firm's type is known to consumers). In the second scenario, information structure is asymmetric across sectors: one sector is mature and firms in that sector have already established reputation (i.e. their types are known) whereas the complementary sector is new and no firm has established reputation. We show that in the absence of consumers' inference problem concerning the true cause of failure, co-branding is irrelevant in relaxing the condition for the existence of separating equilibrium. However, if consumers are unable to identify the true cause of failure, that is, when the final product composed of complementary components fails consumers are unable to tell which component is responsible for the failure, co-branding can alleviate the adverse selection problem.

In the absence of the cross-sector inference problem, it turns out that the total gain from building reputation (or from masquerading as a pair of high types) for any pair of matched types producing complementary components is equal to the sum of each type's stand-alone gain from building reputation. Therefore, a separating equilibrium in which only a pair of high type firms produce exists, regardless of the mode of signaling, as long as a high-type's stand-alone gain from building reputation is larger than a low type's one. This is similar to what happens in the case of single component product. In the presence of the cross-sector inference problem, when a firm owning a good brand chooses a low type firm as its partner, it suffers from a negative feedback effect on its reputation. A low type firm is likely to produce a bad component and therefore the final product produced together with a low type is likely to fail. Since consumers are unable to identify which 
component caused the failure of the final product, a good brand is likely to acquire a failure track record at the end of period one. This negative feedback effect facilitates signaling through co-branding since a firm having a good brand has little incentive to choose a low type firm as its partner. In contrast, when signaling is done with prices in the benchmark of two new sectors, a pair of low type firms can masquerade as a pair of high type firms by charging the same introductory price as the latter. Since a low type firm is less likely to produce a good component than a high type firm, the former suffers less from the negative feedback effect than the latter when each of them is matched with a low type firm: this is obvious when a low type firm produces a bad quality component for sure. Therefore, preventing a pair of low types firms from masquerading as a pair of high types firms can be more difficult than preventing a pair of high type and low type firms from masquerading. This explains why co-branding relaxes the condition to have a separating equilibrium. In Section 5, we apply our insight to different contexts.

\section{The Model with Complementary Components}

We consider a final product that requires two complementary components, $x$ and $y$, to provide useful services to consumers. ${ }^{6}$ There is a continuum of firms producing component $x$ whose mass is normalized to 1 . There is another mass 1 of firms producing component $y$. We consider a two period model in which firms live for two periods. Each firm can produce at most one unit of component output in each period. Consumers are homogeneous in their willingness to pay for the final product and their mass is assumed to be more than 1 in each period. This assumption implies that the sellers are on the short side of the market.

The realization of the quality of each component produced is uncertain; it can be either good or bad. In our model, the complementarity of the two components means that the weakest-link principle prevails in the determination of the final product's quality, that is, the quality of the final product is determined by the lowest quality component. More specifically, we assume that the final product is successful (denoted by $S$ ) in rendering useful service if and only if both components are of good quality. In such a case, the value of service provided by the final product is normalized to 1 . If at least one of the components is of bad quality, the final product fails to provide any service to consumers (denoted by $F$ ) and the product is of zero value.

One implication of the complementary components is that when the final product fails,

\footnotetext{
${ }^{6}$ We can extend the model to the case of more than two complementary inputs $(n>2)$.
} 
consumers may not be able to identify the true cause of failure due to the technological sophistication of the product, i.e., whether it is due to the bad quality of component $x$, $y$, or both components. We consider two cases depending on the ability of consumers to identify the true cause of failure. We first analyze the information structure in which consumers do not have any inference problem concerning the cause of failure. We then investigate the case where consumers are unable to identify the true cause of failure and explore the implications of such inference problem. Firms, however, are assumed to know the true cause of failure and this information is shared among all the firms. The assumption that firms have no inference problem is innocuous and simply allows us to focus on the most efficient outcome through firms' rematch in the second period. This assumption reflects the fact that firms are better informed than consumers due to their experience in production and superiority in technical knowledge. ${ }^{7}$

Firms differ in their ability to produce a good quality component. Let $\theta_{i}^{j}$ represent the type of firm $i \in[0,1]$ that produces component $j$, where $j=x, y$. We assume that there are two types of firms, high $(H)$ and low $(L)$ in each sector, that is, $\theta_{i}^{j} \in\{H, L\}$. If a firm is of high type (resp. of low type), in period one it can produce a good quality component with probability $q_{H}\left(\right.$ resp. $\left.q_{L}\right)$ and a bad quality component with probability $\left(1-q_{H}\right)$ (resp. $1-q_{L}$ ) where $1>q_{H}>q_{L} \geq 0$. The per-period unit cost of producing a component is given by $c_{H}$ and $c_{L}$ for high and low type firms, respectively. The proportion of high type firms in sector $j$ is given by $\nu_{j} \in(0,1)$. The quality realization of each component given each firm's type is i.i.d. Each firm knows its own type while consumers only know the distribution of types. In addition, we assume that all firms know each other's type. Our focus is on imperfect information on the consumer side. This assumption is meant to reflect the fact that firms are able to discern the capability of other firms better than consumers by virtue of being in the same line of business. ${ }^{8}$

We assume that the first period outcomes of each final product ( $S$ or $F$ ) become known to all firms and consumers. Furthermore, we assume that there is some technological learning for the firms from their first period market production. More specifically, each firm's probability of making a good quality component in period two depends both on its

\footnotetext{
${ }^{7}$ Levin and Tadelis (2005) makes a similar assumption in their model of partnerships. More specifically, they consider industries where human capital plays an important role in determining product quality. They assume that clients are at a disadvantage relative to firms in assessing the ability of employees.

${ }^{8}$ Biglaiser (1993) makes a similar assumption in his model of middlemen as experts. A middleman is assumed to be able to ascertain the quality of the good through his investment in human capital such as education or apprenticeships whereas such investment is costly enough so that no buyer is would gain by making an investment.
} 
type and on the quality of its component in period one. To reflect this path dependency, we denote a type $\theta$ firm's probability of producing a good component in period two as $q_{\theta S}^{j}$ and $q_{\theta F}^{j}$, respectively, depending on whether its component was of good quality with successful performance or of bad quality with failed performance in the first period, where $\theta=H, L$ and $j=x, y$. For simplicity, we assume $q_{\theta S}^{x}=q_{\theta S}^{y}=q_{\theta S}$ and $q_{\theta F}^{x}=q_{\theta F}^{y}=q_{\theta F}$. Furthermore, the symmetry in technology allows us to isolate the effect of the cross-sector inference problem. We assume that for each type of firms the probability of producing a good component is higher when they produced a good component in period one than otherwise, that is,

$$
1 \geq q_{\theta S}>q_{\theta F} \geq 0 \text { for } \theta=H, L \text {. }
$$

The role of this assumption is to introduce some residual uncertainty about firms' types in our adverse selection model. As is usual in the literature on reputation, without such an uncertainty, there is no reputation in stake and hence it is impossible to leverage reputation. For instance, a component in period two can be an upgrade of the component produced in period one. In such a case, not only the firm's intrinsic ability (the type) but also its ability specific to the component produced in period one (the past performance) can be a relevant factor. In the extreme case where each firm produces exactly the same component each period, we can even imagine a situation of perfect inter-temporal correlation of quality where $\theta$ is no longer relevant for the second period quality. The opposite extreme case would be a situation in which the component produced in period 2 is completely different from the component produced in period one. As a result, the experience in the first period production is irrelevant and only $\theta$ matters for quality determination in the second period. If a firm's component was not experimented in period one, the probability of having a high-quality component in period two is given by $q_{\theta N}^{x}=q_{\theta N}^{y}=q_{\theta N}$ for $\theta=H, L$ with $q_{\theta N}<q_{\theta F}$. This inequality means that a firm that does not produce in period one is penalized since it does not acquire experience useful for period two production. For instance, we can imagine a situation in which firms' capability depreciates over time without any production. The role of this assumption is to eliminate the possibility that a high type that established its reputation through signaling in period 1 prefers as its period two partner a high type who did not produce in period one to a high type that has a failure record. Let $\delta$ denote the discount factor for the second period payoffs, which is common for all the players.

To demonstrate the role of co-branding as a mechanism to leverage an established firm's reputation, we consider two scenarios. First, as a benchmark, we consider a case where both sectors are new and types of firms in neither sector are known to consumers. 
This case captures a situation in which no firm has yet established its reputation at the beginning of the game. Second, we analyze the case of one-mature-one-new-sector in which types of firms in one sector $(x)$ are already known (hence, a high type firm in sector $x$ is a firm having a good brand) whereas types of firms in the complementary sector $(y)$ are not. This case represents a situation in which firms producing component $x$ have already established their reputation while firms producing component $y$ have yet to establish their reputation. To focus on the situation in which good brands are scare, we assume $\nu_{x}<\nu_{y} .{ }^{9}$ We compare the two cases to derive conditions under which co-branding can play a role in transmitting information about the quality of unknown firms.

Concerning the determination of prices in the market, we consider the following matching technology and bargaining game. In each period there is a random match between a unit of final product and a buyer. The sellers are on the short side. As a result, we assume that the sellers of the final product choose a price and make a take-or-leave-it offer. In particular, this provides the sellers with the possibility to signal their types. In contrast, if we assume that consumers bid up the price of each final product until the price is equalized to the consumers' willingness to pay as in Tadelis (1999) and Cabral (2000), no signaling through price is possible. Since we are interested in how the fact that firms producing one component $(x)$ have established reputation affects the ability of firms producing the complementary component $(y)$ to signal their types, we consider a game in which firms can signal their types through prices. We will compare signaling through prices in the benchmark of two new sectors with signaling through co-branding in the case of one-mature-one-new-sector.

In summary, we make the following assumptions.

A1: (Information Structure) Firms know each other's types. In the case of two new sectors, consumers do not know firm's type in neither sector. In the case of one-matureone-new-sector, they know the types of firms producing component $x$ while they do not know the types of firms producing component $y$.

A2: (With or Without Inference Problem Concerning the Cause of Failure) In the presence of the inference problem, if a final product fails, consumers do not know whether it is due to the failure in component $x$ or $y$ (or due to both). However, firms have no such inference problem.

A3: (Incomplete and Short-Term Contracts) Although the outcomes of each final product realized in period one become known to every player, firms cannot use a contract

\footnotetext{
${ }^{9}$ Our proof can be easily adapted to show that our main result extends to the case of $\nu_{x}=\nu_{y}$ as well.
} 
contingent on the realized outcomes. Firms cannot use a long-term contract. This is true for among themselves and with respect to consumers.

A3 is a standard assumption in the incomplete contract literature a la Hart-GrossmanMoore, which is also adopted by Tadelis (1999), Cabral (2000) and Bar-Issac (forthcoming). ${ }^{10}$ The inability to write contingent contracts can be justified by the problems of verifiability in courts. If outcomes are contractible, firms can use a long-term contract that specifies period two actions contingent on period one outcomes. Because of the incompleteness of contracts, it is natural to consider short-term contracts.

$$
\begin{aligned}
& \mathrm{A} 4: \text { (i) }\left(q_{H}\right)^{2}-2 c_{H}>0>\max \left\{\left(q_{L}\right)^{2}-2 c_{L}, q_{H} q_{L}-c_{H}-c_{L}\right\} \\
& \quad \text { (ii) } q_{H F} q_{H F}-2 c_{H}>0>\max \left\{q_{L S} q_{L S}-2 c_{L}, \max \left\{q_{H S} q_{L S}, q_{L S} q_{H S}\right\}-c_{H}-c_{L}\right\}
\end{aligned}
$$

A4 implies that it is socially desirable for a pair of high type firms to produce in each period while it is socially undesirable for any pair that involves a low type firm to produce in any period. This assumption allows us to focus on the separating equilibrium in which only pairs of high type firms produce.

The timing in the case of two new sectors where firm types in neither sector is known to consumers is given as follows:

- In period one

1. Firms producing each component search for partners in the complementary sector with each firm producing component $x$ being matched to a firm producing component $y$.

2. After matching each pair of matched firms decide whether or not to produce each component (and hence a unit of final product). The production takes place only when both parties agree. Otherwise, they continue to search until a suitable match partner is found. Upon producing a final product, each firm chooses a name to attach to the final product.

3. Each final product is randomly matched to a consumer. Each pair of firms choose a price for the final product and makes a take-it-or-leave-it offer to the consumer. Each consumer decides whether to accept or reject the offer. In case the consumer rejects it, no trade is realized in period one.

4. The outcome of each product is realized and known to all firms and all consumers. Therefore at the end of period one, each firm's name is associated with $S$ or $F$.

\footnotetext{
${ }^{10}$ See Grossman and Hart (1986) and Hart and Moore (1990) for details.
} 
- In period two

1. There will be a new match between firms producing components $x$ and $y$. The match will be based on the information about each firm's type and each firm's past record (the record perceived by consumers and the true record known by firms).

2. Given a pair of matched firms, they decide whether or not to produce each component (and hence a unit of final product). Upon producing a final product, each firm chooses a name (its old name or a new name) and attaches it to the final product.

3. Each final product is matched to a consumer. Each pair of firms choose a price and makes a take-it-or-leave-it offer to the consumer. Each consumer decides whether to accept or reject the offer. In case the consumer rejects it, there is no trade as in the first period.

4. The outcome of each product is realized.

We assume that the match among firms takes place on voluntary basis in that the match will be materialized only when both parties wish to be matched with the other. We also assume that the matching process is instantaneous and does not entail any search costs.

In what follows, we first study a benchmark in which each component $j(=x, y)$ is a final product that can be consumed independently of each other. This benchmark allows us to isolate the effect of having technological complementarity, as is assumed in our model. In all our analysis, we focus on separating equilibria. When there are multiple equilibria, we apply the Cho-Kreps (1987) criterion to eliminate unreasonable equilibria.

\section{Benchmark: Single component product}

In this benchmark, we consider the case of the single component product. Each component $j(=x, y)$ can be consumed as an independent final product and there is no technological complementarity between them. As a consequence, there is no inference problem concerning the cause of failure on the part of consumers when a product fails. We below consider two cases. In the first case, there is no established name in the economy. In the second case, there are some established names in the economy and hence firms in sector $j$ can buy the established names to signal their types. Since each product can be analyzed separately, for notational simplicity, we will dispense with the superscript $j$ in this section if there is no ambiguity. We modify A4 to the single component product case as follows:

A4': (i) $q_{H}>c_{H}>c_{L}>q_{L}$ (ii) $q_{H F}>c_{H}>c_{L}>q_{L S}$ 


\subsection{Price as a Signal without Name Trades}

Consider first the case in which the mean to signal one's type is the price chosen in period one. From A4', in any separating equilibrium, only high type firms sell their products while low type firms do not. Let $p_{1 H}^{S}$ be the price that high type firms choose in period one where the superscript $S$ means "single component good". Obviously, the revised posterior belief of consumers $\nu\left(p_{1 H}^{S}\right)$ is equal to 1 in a separating equilibrium. In addition, let $p_{2 S}^{S}$ and $p_{2 F}^{S}$ respectively denote the price that high type firms with the first period track record of $S$ and $F$ charge in period two. Since firms have bargaining power with respect to consumers, we have:

$$
p_{2 S}^{S *}=q_{H S}, \quad p_{2 F}^{S *}=q_{H F} .
$$

The sufficient and necessary conditions to have a separating equilibrium in which only high types sell in the market are:

$$
\begin{gathered}
\left(\mathrm{IC}_{L^{-}}^{S}\right) \quad p_{1 H}^{S} \leq c_{L}\left(<q_{H}\right) \\
\left(\mathrm{IC}_{L^{-}}^{S}\right) \quad p_{1 H}^{S}-c_{L}+\delta\left[q_{L} p_{2 S}^{S *}+\left(1-q_{L}\right) p_{2 F}^{S *}-c_{L}\right] \leq 0 \\
\left(\mathrm{IC}_{H}^{S}\right) \quad p_{1 H}^{S}-c_{H}+\delta\left[q_{H} p_{2 S}^{S *}+\left(1-q_{H}\right) p_{2 F}^{S *}-c_{H}\right] \geq 0
\end{gathered}
$$

The first two conditions are incentive compatibility constraints for low type firms. Condition $\left(\mathrm{IC}_{L^{-}}^{S}-1\right)$ says that a low type firm has no incentive to sell in period 1 and exit from the market in period 2. Condition $\left(\mathrm{IC}_{L^{-}}^{S}\right.$ ) says that a low type firm has no incentive to mimic a high type firm in both periods either. Condition $\left(\mathrm{IC}_{H}^{S}\right)$ is incentive compatibility constraint for high type firms. Since $p_{2 F}^{*}>c_{H}$ from A4'(ii), $\left(\mathrm{IC}_{L^{-}}^{S}\right)$ is satisfied if $\left(\mathrm{IC}_{L}^{S}-2\right)$ holds. For condition $\left(\mathrm{IC}_{L}^{S}-2\right)$ to hold, we need to have $p_{1 H}^{S} \leq c_{L}-$ $\delta\left[q_{L} q_{H S}+\left(1-q_{L}\right) q_{H F}-c_{L}\right]$ whereas the condition for $\left(\mathrm{IC}_{H}^{S}\right)$ can be rewritten as $p_{1 H}^{S} \geq$ $c_{H}-\delta\left[q_{H} q_{H S}+\left(1-q_{H}\right) q_{H F}-c_{H}\right]$. For these two conditions to be compatible, it is required that

$$
c_{H}-\delta\left[q_{H} q_{H S}+\left(1-q_{H}\right) q_{H F}-c_{H}\right] \leq c_{L}-\delta\left[q_{L} q_{H S}+\left(1-q_{L}\right) q_{H F}-c_{L}\right]
$$

which is equivalent to $c_{H}-c_{L}<\left(q_{H}-q_{L}\right)\left(q_{H S}-q_{H F}\right)$ and $\delta \geq \delta^{S *}$ where $\delta^{S *}$ is defined as

$$
\delta^{S *} \equiv \frac{c_{H}-c_{L}}{\left(q_{H}-q_{L}\right)\left(q_{H S}-q_{H F}\right)-\left(c_{H}-c_{L}\right)} .
$$


This implies that when the condition above holds, any $p_{1 H}^{S} \in\left[c_{H}-\delta\left[q_{H} q_{H S}+\left(1-q_{H}\right) q_{H F}-\right.\right.$ $\left.\left.c_{H}\right], c_{L}-\delta\left[q_{L} q_{H S}+\left(1-q_{L}\right) q_{H F}-c_{L}\right]\right]$ also satisfies condition $\left(\mathrm{IC}_{L}^{S}-1\right)^{11}$ and thus can be supported as a separating equilibrium with the belief $\nu\left(p_{1 H}^{S}\right)=1$ and $\nu\left(p_{1}\right)=0$ for all $p_{1} \neq p_{1 H}^{S}$. Among the continuum of equilibria, the only one surviving the Cho-Kreps (1987) refinement is $p_{1 H}^{S *} \equiv c_{L}-\delta\left[q_{L} q_{H S}+\left(1-q_{L}\right) q_{H F}-c_{L}\right]$. To show this, suppose that in equilibrium high type firms are supposed to choose $p_{1 H}$ belonging to the interval but different from $p_{1 H}^{*}$. Then, high type firms can deviate and choose a price of $\left(p_{1 H}^{S}+\epsilon\right)$, where $\epsilon$ is an infinitesimally small positive number. Since this new price is equilibrium dominated for low type firms, consumers should believe that this price is chosen by a high type firm. Thus, high type firms can profitably deviate upsetting the putative equilibrium. Thus, the only reasonable separating equilibrium price in the first period is $p_{1 H}^{S *} \equiv c_{L}-\delta\left[q_{L} q_{H S}+\left(1-q_{L}\right) q_{H F}-c_{L}\right]$.

Summarizing our results so far, we have:

Proposition 1 In the benchmark case of single component product without name trades;

(i). A separating equilibrium exists if and only if $c_{H}-c_{L}<\left(q_{H}-q_{L}\right)\left(q_{H S}-q_{H F}\right)$ holds and $\delta \geq \delta^{S *}$ where $\delta^{S *}$ is defined as

$$
\delta^{S *} \equiv \frac{c_{H}-c_{L}}{\left(q_{H}-q_{L}\right)\left(q_{H S}-q_{H F}\right)-\left(c_{H}-c_{L}\right)} .
$$

(ii). When the above condition holds, the only first-period price surviving Cho-Kreps criteria is $p_{1 H}^{S *} \equiv(1+\delta) c_{L}-\delta\left[q_{L} q_{H S}+\left(1-q_{L}\right) q_{H F}\right]\left(<c_{L}\right)$ and the second period price is always uniquely given by $p_{2 S}^{*}=q_{H S}, \quad p_{2 F}^{*}=q_{H F}$.

Note that if $q_{H S}=q_{H F}$, there is no separating equilibrium. In other words, a necessary condition to have a separating equilibrium in our model is that a successful performance in period one is appreciated by consumers even though a firm's type is known to be high. Note also that high type firms make a loss in period 1 since the first period equilibrium price $p_{1 H}^{S *}$ is less than its cost of $c_{H}$ to signal their type (i.e., $p_{1 H}^{S *}<c_{L}<c_{H}$ ). Therefore, a separating equilibrium exists only if the second period profit for high type firms is sufficiently large to recoup its loss in the first period.

For the discussion in section 3.2, we introduce some notation. Given $p_{1 H}^{S}$, let $\pi_{H}^{S}\left(p_{1 H}^{S}\right)$ (resp. $\left.\pi_{L}^{S}\left(p_{1 H}^{S}\right)\right)$ represent a high type's (resp. a low type's) gain from being recognized as a high type. In other words, $\pi_{H}^{S}\left(p_{1 H}^{S}\right)$ is equal to the left hand side of $\left(\mathrm{IC}_{H}^{S}\right)$ and $\pi_{L}^{S}\left(p_{1 H}^{S}\right)$ is equal to the left hand side of $\left(\mathrm{IC}_{L^{-}}^{-2}\right)$.

\footnotetext{
${ }^{11}$ This comes form the fact that $q_{L} q_{H S}+\left(1-q_{L}\right) q_{H F}>c_{L}$.
} 


\subsection{Name trades}

In this subsection we allow the possibility of name trades as in Tadelis (1999) and investigate whether such a possibility helps in establishing reputation of firms of unknown type. Suppose now that there is a mass $\nu_{j}$ (or smaller than $\nu_{j}$ ) of good brand names in the economy. Hence, firms in sector $j$ can purchase a good name to signal their type. ${ }^{12}$ We assume that there is unlimited supply of bad brand names and furthermore any firm can introduce a new name without any cost. Each brand name can be sold at most to one firm in sector $j$. We formally study how the possibility of buying an existing brand name affects the condition to have a separating equilibrium. In particular, we are interested in the equilibrium in which the first period belief about the type depends only on whether the brand name is good, bad, or new. In a separating equilibrium, a high type firm buys a good brand name to be attached to its product: i.e. the revised priors are $\nu(G)=1$ and $\nu(B)=\nu(N)=0$ where $G$ represents a good brand name, $B$ represents a bad brand name and $N$ represents a new name. In such an equilibrium, low type firms cannot sell their products and high type firms can sell their products at prices $p_{1 H}^{S * *}=q_{H}$. When only high type firms sell in the first period, the second period prices with the track record of success and failure are respectively given by $p_{2 S}^{S * *}=q_{H S}\left(=p_{2 S}^{S *}\right), p_{2 F}^{S * *}=q_{H F}\left(=p_{2 F}^{S *}\right)$ as in section 3.1.

This implies that a high type firm's maximum willingness to pay for a good brand name is given by:

$$
b_{H}^{S * *}=p_{1 H}^{S * *}-c_{H}+\delta\left[q_{H} p_{2 S}^{S * *}+\left(1-q_{H}\right) p_{2 F}^{S * *}-c_{H}\right] .
$$

In contrast, a low type firm's maximum willingness to pay for a good brand name is given by:

$$
b_{L}^{S * *}=p_{1 H}^{S * *}-c_{L}+\delta\left[q_{B} p_{2 S}^{S * *}+\left(1-q_{B}\right) p_{2 F}^{S * *}-c_{L}\right] .
$$

A separating equilibrium in which only high types buy good names exists if and only if $b_{H}^{S * *} \geq b_{L}^{S * *}$, which is equivalent to $c_{H}-c_{L}<\left(q_{H}-q_{L}\right)\left(q_{H S}-q_{H F}\right)$ and $\delta \geq \delta^{S *}$. Therefore, we conclude

Proposition 2 (i). Consider the benchmark of single component product. Suppose that there is a mass $\nu_{j}$ (or smaller than $v_{j}$ ) of good names in the economy and unlimited supply of bad names.

\footnotetext{
${ }^{12}$ Either we can assume that a firm buys a name for two periods or a firm buys a name only for the first period but at the same time attaches his own name with the bought name such that he can use his own name for the second period.
} 
a. The possibility to buy name does not affect the condition to have a separating equilibrium.

b. In any separating equilibrium, the first-period price is $p_{1 H}^{* *}=q_{H}>p_{1 H}^{*}$ while the second period prices are as in proposition $1 p_{2 S}^{* *}=p_{2 S}^{*}=q_{H S}, p_{2 F}^{* *}=p_{2 F}^{*}=q_{H F}$.

(ii). Therefore, in the absence of technological complementarity, there is no complementarity in reputation building.

Proposition 2(ii) allows us to conclude that in the absence of technological complementarity, having established names in one sector does not help firms in another sector to build their reputations and therefore there is no complementarity in reputation building. The intuition can be given in terms of gain from building reputation. We have:

$$
b_{H}^{S * *}=\pi_{H}^{S}\left(p_{1 H}^{S * *}\right), b_{L}^{S * *}=\pi_{L}^{S}\left(p_{1 H}^{S * *}\right) .
$$

This shows that given $p_{1 H}^{S * *}$, each type's gain from building reputation is not affected by the mode of signaling. Furthermore, what matters for the possibility of signaling is the difference between a high type's gain and a low type's one (i.e. $\pi_{H}^{S}\left(p_{1 H}^{S}\right)-\pi_{H}^{S}\left(p_{1 H}^{S}\right)$ ), which is independent of $p_{1 H}^{S}$. Therefore, the mode of signaling does not affect the condition under which a signaling equilibrium exists.

Remark 1: The result of proposition 2 seems to be a little bit puzzling. In some cases, buying a good name seems to be a more effective way of signaling than signaling through a low price. For instance, consider the market for perfumes. Many perfumes use names of famous fashion designers as their own product names even though the fashion designer in question has not designed neither the shape of the bottle nor its odor. In reality, there can be some reasons which make the signaling through name more effective than signaling through low prices. First, if $p_{1 H}^{S *}<0$, charging a negative price can attract fake consumers who do not value the product at all such that they just enjoy the free gift, which would make signaling very costly. Second, when $p_{1 H}^{S *}>0$, a low price can trigger the entry of really bad products. For instance, suppose that there is a large number of firms who can produce very bad quality product $y$ at a very low cost such that a consumer's benefit from using that good is almost zero while the cost of producing it is lower than $p_{1 H}^{S *}$. Then, these firms can make a positive profit by entering the market at price $p_{1 H}^{S *}$. By contrast, signaling through names does not suffer neither from fake consumers' seeking for free gift nor from pooling with very bad quality products.

Remark 2: It is interesting to note different price dynamics depending on the mode of signaling. Since in our model, the quantity that a firm produces each period is fixed, 
the difference in price dynamics does not affect social welfare. In a richer model in which quantity is endogenous, a high first period price under signaling with names would generate lower consumer surplus than a low first period price under signaling with price.

\section{Complementary Case with Two Sectors}

We now consider the case in which a final product is composed of two complementary components as described in the model. In this section, we investigate a mechanism in which the reputation of firms in one component sector can be leveraged to build reputation of other firms in the complementary sector. To investigate this issue, we consider two scenarios. In the first scenario, both sectors are new and firms in neither sector established reputation. In the second scenario, information structure in asymmetric across sectors: one sector is mature and firms in that sector have already established reputation whereas the complementary sector is new and no firm has established reputation.

In the first scenario, price is used to signal the quality of the final product. In the second scenario, we ask the question of whether co-branding with established firms can be used as an alternative signal for firms with unknown quality. We find that the answer is affirmative and derive conditions under which co-branding is a more effective way to signal quality than pricing alone. In particular, we highlight the importance of the consumers' inference problem in identifying the true cause of failure when a final product fails to perform. We show that co-branding has a bite as an instrument of signal when consumers have the inference problem.

We are interested in a separating equilibrium in which the firm types are revealed to consumers through signaling. With our parametric assumption A4, this implies that only high types are able to sell in the first period and all remaining firms in the second period are high types. As usual, we analyze the conditions for the existence of a separating equilibrium by applying backward induction.

\subsection{The Second Period}

We focus on separating equilibrium in which firm types are revealed to consumers. This implies that only high types remain in the market and their types are known to consumers in the second period. As a result, the second period analysis is the same, independent of the mode of signaling used in the first period.

Regardless of the initial information structure across the sectors at the beginning of 
the game, both sectors are symmetric ex post in the beginning of second period in a separating equilibrium in which only pairs of high type firms produce in the first period. Thus, we assume that in period two, revenue is equally divided within a pair of high type firms with the same past record (perceived by consumers). We below show that there exists an equilibrium with positive sorting in the second period. Note that in the second period, every pair of firms charges a price equal to a consumer's maximum willingness to pay for the final product given his information about the firms' types and their previous records.

Consider first the case without consumers' inference problem, that is, consumers are able to identify the true cause of the failure when the final product fails. Let $p_{S F}^{2 N}$ denote the prices charged by a pair composed of a high type in sector $x$ with a success record and a high type in sector $y$ with a failure record: the superscript $N$ means no inference problem. We define $p_{S S}^{2 N}, p_{F S}^{2 N}$ and $p_{F F}^{2 N}$ in a similar way. Then, we have:

$$
p_{S S}^{2 N}=\left(q_{H S}\right)^{2}, p_{S F}^{2 N}=p_{F S}^{2 N}=q_{H S} q_{H F}, p_{F F}^{2 N}=\left(q_{H F}\right)^{2} .
$$

With the assumption of the equal division of revenue within an $S S$ pair (and within an FF pair), the expected payoff of a firm with a success record (respectively, with a failure record) under positive sorting is $p_{S S}^{2 N} / 2-c_{H}$ (respectively, $p_{F F}^{2 N} / 2-c_{H}$ ). We now show that positive sorting takes place as an equilibrium, that is, no firm with a success record has an incentive to be matched with a firm with a failure record. Suppose, to the contrary, that a firm in sector $x$ with a success record is matched with a firm in sector $y$ with a failure record. In this case, their joint revenue is $p_{S F}^{2 N}$. For this deviation to be profitable, their joint revenue $\left(p_{S F}^{2 N}\right)$ should exceed that achievable under positive sorting, that is, $\frac{p_{S S}^{2 N}+p_{F F}^{2 N}}{2}$. However, we have

$$
p_{S F}^{2 N}=q_{H S} q_{H F}<\frac{p_{S S}^{2 N}+p_{F F}^{2 N}}{2}=\frac{\left(q_{H S}\right)^{2}+\left(q_{H F}\right)^{2}}{2} .
$$

This implies that such a deviation cannot be profitable for both parties; positive sorting arises as an equilibrium outcome and no firm with success record has incentives to be matched with a firm with failure record in the second period.

Consider now the case with consumers' inference problem in that they cannot identify the true cause of failure when a final product fails. Let $p_{S F}^{2 I}$ denote the prices charged by a pair composed of a high type in sector $x$ with a success record and a high type in sector $y$ with a failure record: the superscript $I$ means inference problem. We define $p_{S S}^{2 I}, p_{F S}^{2 I}$ and $p_{F F}^{2 I}$ in a similar way. Obviously, we have $p_{S S}^{2 I}=\left(q_{H S}\right)^{2}\left(=p_{S S}^{2 I}\right)$. We focus on the most efficient equilibrium in which among the firms with a failure record (i.e. among those 
whose final products failed in the first period), the successful producers of component $x$ are matched with the successful producers of component $y$ and similarly for the producers of failed components. In such an equilibrium, we have

$$
p_{F F}^{2 I}=\frac{q_{H}}{1+q_{H}}\left(q_{H S}\right)^{2}+\frac{1}{1+q_{H}}\left(q_{H F}\right)^{2} .
$$

The equal division of revenue within an $S S$ pair (and within an $F F$ pair) implies that the expected payoff of a firm with a success record (respectively, with a failure record) is $p_{S S}^{2 I} / 2-c_{H}$ (respectively, $p_{F F}^{2 I} / 2-c_{H}$ ). Once again, we show that positive sorting arises as an equilibrium. As in the case without the inference problem, let us consider a deviation in which a firm in sector $x$ with success record is matched with a firm in sector $y$ with failure record. If consumers expect that the firm with a failure record is randomly chosen for matching with a success record, their maximum willingness to pay for a final product produced by an $S F$ pair is given by:

$$
p_{S F}^{2 I}\left(=p_{F S}^{2 I}\right)=\frac{q_{H}}{1+q_{H}}\left(q_{H S}\right)^{2}+\frac{1}{1+q_{H}} q_{H S} q_{H F} .
$$

For the deviation to be profitable, their joint revenue $\left(p_{S F}^{2 I}\right)$ should exceed that achievable under positive sorting, that is, $\frac{p_{S S}^{2 I}+p_{F F}^{2 I}}{2}$. However, we have

$$
\begin{aligned}
p_{S F}^{2 I} & =\frac{q_{H}}{1+q_{H}}\left(q_{H S}\right)^{2}+\frac{1}{1+q_{H}} q_{H S} q_{H F} \\
& <\frac{q_{H}}{1+q_{H}}\left(q_{H S}\right)^{2}+\frac{1}{1+q_{H}} \frac{\left(q_{H S}\right)^{2}+\left(q_{H F}\right)^{2}}{2} \\
& =\frac{1}{2}\left(q_{H S}\right)^{2}+\frac{1}{2}\left[\frac{q_{H}}{1+q_{H}}\left(q_{H S}\right)^{2}+\frac{1}{1+q_{H}}\left(q_{H F}\right)^{2}\right]=\frac{p_{S S}^{2 I}+p_{F F}^{2 I}}{2} .
\end{aligned}
$$

Therefore, such a deviation is not profitable and positive sorting with the same record is an equilibrium.

\subsection{The First Period}

\subsubsection{General result}

We first derive a general result that holds regardless of the existence of consumers' inference problem.

Consider the first scenario in which both sectors are new and the instrument of signaling is price. Suppose that a pair of high types charges $p_{H H}^{1}$ in the first period price in a separating equilibrium. Given $p_{H H}^{1}$, let $V_{H H}^{N}\left(p_{H H}^{1}\right)$ denote the present discounted values 
of the total payoffs that a pair of high types realize over two periods in a separating equilibrium when there is no inference problem. Then, we have

$$
V_{H H}^{N}\left(p_{H H}^{1}\right) \equiv p_{H H}^{1}-2 c_{H}+2 \delta\left\{q_{H}\left[p_{S S}^{2 N} / 2\right]+\left(1-q_{H}\right)\left[p_{F F}^{2 N} / 2\right]-c_{H}\right\} .
$$

The corresponding value in the presence of the inference problem is denoted by $V_{H H}^{I}\left(p_{H H}^{1}\right)$, which is given by

$$
V_{H H}^{I}\left(p_{H H}^{1}\right) \equiv p_{H H}^{1}-2 c_{H}+\delta\left\{\left(q_{H}\right)^{2}\left[p_{S S}^{2 I}\right]+\left(1-\left(q_{H}\right)^{2}\right)\left[p_{F F}^{2 I}\right]-c_{H}\right\} .
$$

Note that in the presence of the inference problem, the firms will be able to charge the price $p_{S S}^{2 I}$ in period two only if both components were successful in period one. To present a result that holds regardless of the existence of the inference problem, we use superscript $h=N, I$.

Similarly, given information structure $h$, let $V_{H L}^{h}\left(p_{H H}^{1}\right)$ denote the present value of total joint payoffs that an $H L$ pair (i.e., a pair composed of a high type in sector $x$ and a low type in sector $y$ ) realize over two periods when they masquerade as an $H H$ pair by charging $p_{H H}^{1}$ in period one. $V_{L H}^{h}\left(p_{H H}^{1}\right)$ and $V_{L L}^{h}\left(p_{H H}^{1}\right)$ are similarly defined and by symmetry, we have $V_{H L}^{h}\left(p_{H H}^{1}\right)=V_{L H}^{h}\left(p_{H H}^{1}\right)$. More specifically,

$$
\begin{aligned}
& V_{H L}^{N}\left(p_{H H}^{1}\right) \equiv p_{H H}^{1}-c_{H}-c_{L}+\delta\left\{q_{H}\left[p_{S S}^{2 N} / 2\right]+\left(1-q_{H}\right)\left[p_{F F}^{2 N} / 2\right]-c_{H}\right. \\
&\left.+q_{L}\left[p_{S S}^{2 N} / 2\right]+\left(1-q_{L}\right)\left[p_{F F}^{2 N} / 2\right]-c_{L}\right\} ; \\
& V_{L L}^{N}\left(p_{H H}^{1}\right) \equiv p_{H H}^{1}-2 c_{L}+2 \delta\left\{q_{L}\left[p_{S S}^{2 N} / 2\right]+\left(1-q_{L}\right)\left[p_{F F}^{2 N} / 2\right]-c_{L}\right\} . \\
& V_{H L}^{I}\left(p_{H H}^{1}\right) \equiv p_{H H}^{1}-c_{H}-c_{L}+\delta\left\{q_{H} q_{L} p_{S S}^{2 I}+\left(1-q_{H} q_{L}\right) p_{F F}^{2 I}-c_{H}-c_{L}\right\} ; \\
& V_{L L}^{I}\left(p_{H H}^{1}\right) \equiv p_{H H}^{1}-2 c_{L}+\delta\left\{\left(q_{L}\right)^{2} p_{S S}^{2 I}+\left(1-\left(q_{L}\right)^{2}\right)\left[p_{F F}^{2 I}\right]-2 c_{L}\right\} .
\end{aligned}
$$

Let us define $\Delta_{H H, H L}^{h} \equiv V_{H H}^{h}\left(p_{H H}^{1}\right)-V_{H L}^{h}\left(p_{H H}^{1}\right), \Delta_{H L, L L}^{h} \equiv V_{H L}^{h}\left(p_{H H}^{1}\right)-V_{L L}^{h}\left(p_{H H}^{1}\right)$, and $\Delta_{H H, L L}^{h} \equiv V_{H H}^{h}\left(p_{H H}^{1}\right)-V_{L L}^{h}\left(p_{H H}^{1}\right)$. Note that $\Delta_{H H, H L}^{h}, \Delta_{H L, L L}^{h}$ and $\Delta_{H H, L L}^{h}$ do not depend on $p_{H H}^{1}$.

When signaling is done with prices, in order to have a separating equilibrium in which only $H H$ pairs produce in the first period, $V_{H H}^{h}\left(p_{H H}^{1}\right) \geq 0$ and $V_{L L}^{h}\left(p_{H H}^{1}\right) \leq 0$ must hold. Furthermore, from $\nu_{x}<\nu_{y}$, there remain some high type firms in sector $y$ which cannot be matched to high types in sector $x$. These firms can be matched to low types in sector $x$. Therefore, $V_{L H}^{h}\left(p_{H H}^{1}\right) \leq 0$ also must hold. We have the following lemma: 
Lemma 1 Consider signaling with prices when both sectors are new. For a given information structure $h=N$ or $I$, the separating equilibrium exists if and only if $\Delta_{H H, H L}^{h} \geq 0$ and $\Delta_{H H, L L}^{h} \geq 0$.

Proof. The previous argument shows that if the separating equilibrium exists, $\Delta_{H H, H L}^{h} \geq$ 0 and $\Delta_{H H, L L}^{h} \geq 0$ hold. We now prove the reverse part, that is, if the conditions $\Delta_{H H, H L}^{h} \geq 0$ and $\Delta_{H H, L L}^{h} \geq 0$ hold, there exists a separating equilibrium. Consider a first period final product price $p_{H H}^{1 h *}\left(\leq\left(q_{H}\right)^{2}\right)$ such that $V_{H H}^{h}\left(p_{H H}^{1 h *}\right) \geq 0, V_{L L}^{h}\left(p_{H H}^{1 h *}\right) \leq$ 0 and $V_{H L}^{h}\left(p_{H H}^{1 h *}\right) \leq 0$. Note that such a $p_{H H}^{1 h *}$ exists. To see this, notice that all $V_{H H}^{h}\left(p_{H H}^{1 h *}\right), V_{L L}^{h}\left(p_{H H}^{1 h *}\right)$, and $V_{H L}^{h}\left(p_{H H}^{1 h *}\right)$ strictly increases in $p_{H H}^{1 h *}$. Let $\bar{p}_{H H}^{1 h *}$ and $\underline{p}_{H H}^{1 h *}$ be uniquely defined by $\max \left\{V_{H L}^{h}\left(\bar{p}_{H H}^{1 h *}\right), V_{L L}^{h}\left(\bar{p}_{H H}^{1 h *}\right)\right\}=0$ and $V_{H H}^{h}\left(\underline{p}_{H H}^{1 h *}\right)=0$, respectively. If $\Delta_{H H, H L}^{h} \geq 0$ and $\Delta_{H H, L L}^{h} \geq 0$, then it is clear that $\bar{p}_{H H}^{1 h *} \geq \underline{p}_{H H}^{1 h *}$. In addition, for any $p_{H H}^{1 h *} \in\left[\underline{p}_{H H}^{1 h *}, \bar{p}_{H H}^{1 h *}\right]$ we have $V_{H H}^{h}\left(p_{H H}^{1 h *}\right) \geq 0, V_{L L}^{h}\left(p_{H H}^{1 h *}\right) \leq 0$ and $V_{H L}^{h}\left(p_{H H}^{1 h *}\right) \leq 0$. Therefore, we have a continuum of separating equilibria that can be supported with appropriate beliefs if $\bar{p}_{H H}^{1 h *}>\underline{p}_{H H}^{1 h *}$. However, the only equilibrium that survives the Cho-Kreps refinement criterion is the equilibrium in which $H H$ pairs charge $p_{H H}^{1 h *}=\bar{p}_{H H}^{1 h *}$. Since $\max \left\{V_{L L}^{h}\left(p_{H H}^{1 h *}=\bar{p}_{H H}^{1 h *}\right), V_{H L}^{h}\left(p_{H H}^{1 h *}=\bar{p}_{H H}^{1 h *}\right)\right\}=0$, any pair including at least one low type has no incentive to mimic the price charged by $H H$ pairs. Competition among high type firms in sector $y$ to be matched with high type firms in sector $x$ affects the revenue sharing within an $H H$ pair such that in any $H H$ pair, the high type firm in sector $y$ gets zero payoff; if it realizes any strictly positive payoff, then a high type firm in sector $y$ which is not matched to a high type firm in $x$ can make a bid for a smaller payoff to be matched with a high type firm in $x$, upsetting the putative equilibrium. Since $V_{H H}^{h}\left(p_{H H}^{1 h *}=\bar{p}_{H H}^{1 h *}\right) \geq 0$ $\left(V_{H H}^{h}\left(p_{H H}^{1 h *}=\bar{p}_{H H}^{1 h *}\right)>0\right.$ if $\left.\bar{p}_{H H}^{1 h *}>\underline{p}_{H H}^{1 h *}\right)$, any high type in sector $x$ has an incentive to be matched with a high type firm in sector $y$ and to sell the final product at price $p_{H H}^{1 h *}=\bar{p}_{H H}^{1 h *}$.

Consider now an alternative scenario in which sector $x$ is mature and sector $y$ is new. We investigate the possibility that the existence of established firms in sector $x$ enables new firms in sector $y$ to signal their quality with co-branding. In a separating equilibrium with co-branding, no firm can sell its product without being associated with good brands in sector $x$. Since good brand names are relatively scarce (i.e. $\nu_{x}<\nu_{y}$ ), good brand firms in sector $x$ will have all bargaining power with respect to their partners in sector $y$, implying that firms in sector $y$ will have zero payoff. We have the following lemma:

Lemma 2 Consider signaling with co-branding when sector $x$ is mature and sector $y$ is new. For a given information structure $h=N$ or $I$, the separating equilibrium exists if and only if $\Delta_{H H, H L}^{h} \geq 0$. 
Proof. Suppose that the separating equilibrium exists. Then, an $H H$ pair will charge in period one $p_{H H}^{1 h * *}=\left(q_{H}\right)^{2}$. Since a good brand firm in sector $x$ has all the bargaining power with respect to its partner, it gets $V_{H H}^{h}\left(p_{H H}^{1 h * *}\right)$ if it is matched with a high type in sector $y$. Instead, if it deviates and is matched with a low type in sector $y$ and charges $p_{H H}^{1 h * *}$, it gets $V_{H L}^{h}\left(p_{H H}^{1 h * *}\right)$. For the separating equilibrium to exist, $V_{H H}^{h}\left(p_{H H}^{1 h * *}\right)-V_{H L}^{h}\left(p_{H H}^{1 h * *}\right)=$ $\Delta_{H H, H L}^{h} \geq 0$ must hold.

Conversely, suppose that $\Delta_{H H, H L}^{h} \geq 0$. Then, we have $V_{H H}^{h}\left(p_{H H}^{1 h * *}\right) \geq 0$ and $V_{H H}^{h}\left(p_{H H}^{1 h * *}\right) \geq$ $V_{H L}^{h}\left(p_{H H}^{1 h * *}\right)$. Therefore, the separating equilibrium with co-branding exists.

From both lemmas, we have the following Proposition.

Proposition 3 For a given information structure $h=N$ or $I$, if the separating equilibrium with prices exists when both sectors are new, then the separating equilibrium with co-branding exists when sector $x$ is mature and sector $y$ is new.

In order to provide an intuition about the result in the proposition, we first note that regardless of the mode of signaling, $\nu_{x}<\nu_{y}$ implies that a high type in sector $x$ has all bargaining power with respect to his partner from sector $y$. Under signaling with co-branding, an $H H$ pair will charge in period one $p_{H H}^{1 h * *}=\left(q_{H}\right)^{2}$ and we always have $V_{H H}\left(p_{H H}^{1 h * *}\right)>0$. Therefore, the signaling equilibrium exists if and only if a high type in sector $x$ prefers being matched to a high type instead of being matched to a low type and this condition is given by $\Delta_{H H, H L}^{h} \geq 0$. In contrast, under signaling with prices, this condition is only a necessary one since a low type in sector $x$ can be matched either to a high type or a low type in sector $y$ to masquerade as an $H H$ pair by charging the first period price equal to $p_{H H}^{1 *}$, the price charged by an $H H$ pair. In order to make such a deviation not profitable, we need an additional condition, that is, $p_{H H}^{1 h *}$ must be such that $V_{L H}^{h}\left(p_{H H}^{1 h *}\right) \leq 0$ and $V_{L L}^{h}\left(p_{H H}^{1 h *}\right) \leq 0$ hold. These conditions and $V_{H H}^{h}\left(p_{H H}^{1 h *}\right) \geq 0$ are satisfied only if $\Delta_{H H, H L}^{h} \geq 0$ and $\Delta_{H H, L L}^{h} \geq 0$. In summary, under signaling with co-branding, low type firms in sector $x$ cannot sell their products simply because their brands are known to be of low quality. This relaxes the condition to have a separating equilibrium vis-a-vis signaling with prices.

The proposition essentially says that the condition to have a separating equilibrium is weakly less stringent under signaling with co-branding than under signalling with prices. We now investigate when the condition for a separating equilibrium is strictly less stringent under signaling with co-branding. We demonstrate that the incentive compatibility condition $\Delta_{H H, L L}^{h} \geq 0$ is a non-binding constraint under signaling with prices when consumers do not have the inference problem. As a result, co-branding has no bite in the 
absence of the inference problem. However, the condition becomes a binding constraint when consumers have the inference problem concerning the true cause of failure. In such a case, co-branding strictly relaxes the condition for the existence of a separating equilibrium and has the potential to be a more effective instrument of signaling.

\subsubsection{No inference problem}

Suppose that there is no inference problem and consumers can identify the culprit of the failure when the final product fails to perform. In such a case, the following lemma states that the additional constraint under signaling with prices, $\Delta_{H H, L L}^{N} \geq 0$, is redundant.

Lemma 3 When consumers have no inference problem (i.e. $h=N), \Delta_{H H, H L}^{N}=\Delta_{H L, L L}^{N}$.

Proof. We have

$$
\begin{gathered}
V_{H H}^{N}\left(p_{H H}^{1}\right) \equiv p_{H H}^{1}-2 c_{H}+2 \delta\left\{q_{H}\left[p_{S S}^{2 N} / 2\right]+\left(1-q_{H}\right)\left[p_{F F}^{2 N} / 2\right]-c_{H}\right\} ; \\
V_{H L}^{N}\left(p_{H H}^{1}\right) \equiv \quad \begin{aligned}
1 & p_{H H}-c_{H}-c_{L} \\
& +\delta\left\{q_{H}\left[p_{S S}^{2 N} / 2\right]+\left(1-q_{H}\right)\left[p_{F F}^{2 N} / 2\right]-c_{H}+q_{L}\left[p_{S S}^{2 N} / 2\right]+\left(1-q_{L}\right)\left[p_{F F}^{2 N} / 2\right]-c_{L}\right\} ;
\end{aligned} \\
V_{L L}^{N}\left(p_{H H}^{1}\right) \equiv p_{H H}^{1}-2 c_{L}+2 \delta\left\{q_{L}\left[p_{S S}^{2 N} / 2\right]+\left(1-q_{L}\right)\left[p_{F F}^{2 N} / 2\right]-c_{L}\right\} .
\end{gathered}
$$

Therefore,

$$
\Delta_{H H, H L}^{N}=\Delta_{H L, L L}^{N}=-(1+\delta)\left(c_{H}-c_{L}\right)+\delta \frac{\left(q_{H}-q_{L}\right)}{2}\left[\left(q_{H}\right)^{2}-\left(q_{L}\right)^{2}\right] .
$$

Note that $\Delta_{H H, L L}^{N}=V_{H H}^{N}\left(p_{H H}^{1}\right)-V_{L L}^{N}\left(p_{H H}^{1}\right)=\left[V_{H H}^{N}\left(p_{H H}^{1}\right)-V_{H L}^{N}\left(p_{H H}^{1}\right)\right]+\left[V_{H L}^{N}\left(p_{H H}^{1}\right)-\right.$ $\left.V_{L L}^{N}\left(p_{H H}^{1}\right)\right]=\Delta_{H H, H L}^{N}+\Delta_{H L, L L}^{N} . \quad$ Lemma 3 thus implies that $\Delta_{H H, L L}^{N}=2 \Delta_{H H, H L}^{N}$. Therefore, $\operatorname{sign}\left(\Delta_{H H, L L}^{N}\right)=\operatorname{sign}\left(\Delta_{H L, H L}^{N}\right)$, that is, $\Delta_{H H, H L}^{N} \geq 0$ if and only if $\Delta_{H H, L L}^{N} \geq 0$. As a consequence, we have the following proposition that states the equivalence between signaling with prices and signaling with co-branding when the true cause of failure can be identified by consumers when the final product fails to perform.

Proposition 4 In the absence of consumers' inference problem, technological complementarity does not imply complementarity in reputation building (i.e. the condition to have a separating equilibrium does not depend on the mode of signaling). The condition for the 
existence of separating equilibrium $\left(\Delta_{H H, L L}^{N}=2 \Delta_{H H, H L}^{N} \geq 0\right)$ can be stated equivalently in terms of primitive parameters as follows:

$$
\begin{aligned}
A^{N *} & \equiv \frac{\left[q_{H}-q_{L}\right]}{2}\left[\left(q_{H S}\right)^{2}-\left(q_{H F}\right)^{2}\right]>\left(c_{H}-c_{L}\right) \\
\text { and } \delta & \geq \delta^{N *} \equiv \frac{c_{H}-c_{L}}{A^{N *}-\left(c_{H}-c_{L}\right)} .
\end{aligned}
$$

In order to provide an intuition of the result of the above proposition, define the stand-alone gain from building reputation as follows: ${ }^{13}$

$$
\pi_{\theta}^{S A}\left(p_{H H}^{1}, p_{S S}^{2 N}, p_{F F}^{2 N}\right)=\frac{p_{H H}^{1}}{2}-c_{\theta}+\delta\left[q_{\theta}\left(p_{S S}^{2 N} / 2\right)+\left(1-q_{\theta}\right)\left(p_{F F}^{2 N} / 2\right)-c_{\theta}\right] \text { for } \theta=H, L .
$$

$\pi_{\theta}^{S A}$ represents a $\theta$-type firm's (expected) profit when consumers believe that it is a high type firm. Then, a $\theta \theta^{\prime}$ pair's total payoff from masquerading as an $H H$ pair is given as follows:

$$
V_{\theta \theta^{\prime}}^{N}=\pi_{\theta}^{S A}+\pi_{\theta^{\prime}}^{S A} \text { for } \theta, \theta^{\prime} \in\{H, L\}^{2} .
$$

The equation tells that in the absence of the inference problem, the type of a firm's partner has no impact on the firm's gain from building reputation. Therefore, we have:

$$
V_{H H}^{N}-V_{L L}^{N}=2\left(V_{H H}^{N}-V_{H L}^{N}\right)=2\left(\pi_{H}^{S A}-\pi_{L}^{S A}\right) .
$$

Hence, the mode of signaling is irrelevant for the existence of separating equilibrium. The separating equilibrium exists as long as a high type's stand-alone gain from building reputation is higher than that of a low type, which is the intuition we found in the previous section on the single component product.

\subsubsection{Inference problem}

Suppose that consumers face an inference problem in that they cannot identify the true cause of failure when the final product fails. In such a case, we demonstrate that cobranding relaxes the condition for the existence of a separating equilibrium. In other words, when one sector is mature and firms in that sector have established reputation, co-branding may allow firms in the new sector signal the quality that they could not signal with prices when both sectors are new. The following lemma shows that the additional constraint under signaling with prices is more stringent than the one under signaling with co-branding and thus can be a binding constraint in the presence of the inference problem.

\footnotetext{
${ }^{13}$ In the definition, we assume equal sharing of the period one revenue for expositional facility; this assumption is not needed for the arguments we make.
} 
Lemma 4 When consumers face an inference problem (i.e. $h=I), \Delta_{H H, H L}^{I}-\Delta_{H L, L L}^{I}=$ $\delta \frac{\left(q_{H}-q_{L}\right)^{2}}{1+q_{H}}\left[\left(q_{H}\right)^{2}-\left(q_{L}\right)^{2}\right]>0$.

Proof. We have

$$
\begin{gathered}
V_{H H}^{I}\left(p_{H H}^{1}\right) \equiv p_{H H}^{1}-2 c_{H}+\delta\left\{\left(q_{H}\right)^{2} p_{S S}^{2 I}+\left(1-\left(q_{H}\right)^{2}\right) p_{F F}^{2 I}-2 c_{H}\right\} \\
V_{H L}^{I}\left(p_{H H}^{1}\right) \equiv p_{H H}^{1}-c_{H}-c_{L}+\delta\left\{q_{H} q_{L} p_{S S}^{2 I}+\left(1-q_{H} q_{L}\right) p_{F F}^{2 I}-c_{H}-c_{L}\right\} ; \\
V_{L L}^{I}\left(p_{H H}^{1}\right) \equiv p_{H H}^{1}-2 c_{L}+\delta\left\{\left(q_{L}\right)^{2} p_{S S}^{2 I}+\left(1-\left(q_{L}\right)^{2}\right)\left[p_{F F}^{2 I}\right]-2 c_{L}\right\} .
\end{gathered}
$$

Therefore,

$$
\begin{aligned}
\Delta_{H H, H L}^{I}-\Delta_{H L, L L}^{I} & =\left[V_{H H}^{I}\left(p_{H H}^{1}\right)-V_{H L}^{I}\left(p_{H H}^{1}\right)\right]-\left[V_{H L}^{I}\left(p_{H H}^{1}\right)-V_{L L}^{I}\left(p_{H H}^{1}\right)\right] \\
& =\delta\left(q_{H}-q_{L}\right)^{2}\left[p_{S S}^{2 I}-p_{F F}^{2 I}\right]=\delta \frac{\left(q_{H}-q_{L}\right)^{2}}{1+q_{H}}\left[\left(q_{H S}\right)^{2}-\left(q_{H F}\right)^{2}\right]>0 .
\end{aligned}
$$

The lemma implies that it is possible to have $\Delta_{H H, H L}^{I} \geq 0$ and $\Delta_{H H, L L}^{I}<0$ at the same time. To see this, notice that $\Delta_{H H, L L}^{I}=\Delta_{H H, H L}^{I}+\Delta_{H L, L L}^{I}$. Therefore, the condition for $\Delta_{H H, L L}^{I}<0$ can be written as $\Delta_{H H, L L}^{I}=\Delta_{H H, H L}^{I}+\Delta_{H L, L L}^{I}=\left\{\Delta_{H L, L L}^{I}+\right.$ $\left.\delta \frac{\left(q_{H}-q_{L}\right)^{2}}{1+q_{H}}\left[\left(q_{H}\right)^{2}-\left(q_{L}\right)^{2}\right]\right\}+\Delta_{H L, L L}^{I}<0 . \quad$ As a result, we can have $\Delta_{H H, H L}^{I} \geq 0$ and $\Delta_{H H, L L}^{I}<0$ be satisfied simultaneously when the following condition holds:

$$
-\delta \frac{\left(q_{H}-q_{L}\right)^{2}}{1+q_{H}}\left[\left(q_{H S}\right)^{2}-\left(q_{H F}\right)^{2}\right] \leq \Delta_{H L, L L}^{I}<-\delta \frac{\left(q_{H}-q_{L}\right)^{2}}{2\left(1+q_{H}\right)}\left[\left(q_{H S}\right)^{2}-\left(q_{H F}\right)^{2}\right] .
$$

By using the explicit expression for $\Delta_{H L, L L}^{I}\left(=V_{H L}^{I}\left(p_{H H}^{1}\right)-V_{L L}^{I}\left(p_{H H}^{1}\right)=-(1+\delta)\left(c_{H}-c_{L}\right)+\right.$ $\left.\delta \frac{q_{L}\left[q_{H}-q_{L}\right]}{\left(1+q_{H}\right)}\left[\left(q_{H S}\right)^{2}-\left(q_{H F}\right)^{2}\right]\right)$, we can rewrite the condition above in terms of primitive parameters:

$\frac{\left(q_{H}+q_{L}\right)\left(q_{H}-q_{L}\right)}{2\left(1+q_{H}\right)}\left[\left(q_{H S}\right)^{2}-\left(q_{H F}\right)^{2}\right]<\frac{(1+\delta)}{\delta}\left(c_{H}-c_{L}\right) \leq \frac{q_{H}\left[q_{H}-q_{L}\right]}{1+q_{H}}\left[\left(q_{H S}\right)^{2}-\left(q_{H F}\right)^{2}\right]$.

We have:

Proposition 5 In the presence of consumers' inference problem, technological complementarity implies complementarity in reputation building (i.e. the condition to have a 
separating equilibrium is less stringent under signaling with co-branding than under signaling with prices). More precisely, if the following inequality holds

$$
\frac{\left(q_{H}+q_{L}\right)\left(q_{H}-q_{L}\right)}{2\left(1+q_{H}\right)}\left[\left(q_{H S}\right)^{2}-\left(q_{H F}\right)^{2}\right]<\frac{(1+\delta)}{\delta}\left(c_{H}-c_{L}\right) \leq \frac{q_{H}\left[q_{H}-q_{L}\right]}{1+q_{H}}\left[\left(q_{H S}\right)^{2}-\left(q_{H F}\right)^{2}\right]
$$

the separating equilibrium exists under signaling with co-branding but does not exist under signaling with prices.

In order to provide an intuition of the result of the above proposition, consider the simple case in which $q_{H}>q_{L}=0$. In this particular case, we have

$$
\begin{aligned}
V_{H L}^{I} & =p_{H H}^{1}-c_{H}-c_{L}+\delta\left\{p_{F F}^{2 I}-c_{H}-c_{L}\right\} \\
V_{L L}^{I} & =p_{H H}^{1}-c_{L}-c_{L}+\delta\left\{p_{F F}^{2 I}-c_{L}-c_{L}\right\} .
\end{aligned}
$$

Therefore, when $c_{H}>c_{L}$, which we assume, we have $V_{L L}^{I}>V_{H L}^{I}$. As a consequence, satisfying $\Delta_{H H, L L}^{I}=V_{H H}^{I}-V_{L L}^{I} \geq 0$ is more difficult than satisfying $\Delta_{H H, H L}^{I}=V_{H H}^{I}-$ $V_{H L}^{I} \geq 0$. This implies that signaling through prices is more difficult than signaling through co-branding. Intuitively, in the case of one-mature-one-new sectors, a good brand firm in the mature sector has little incentive to choose as its partner a low type firm in the new sector because of the negative feed-back effect on its reputation; when $q_{L}=0$, the final product produced together with a low type will fail for sure and therefore the good brand's reputation will be sullied from a failure record. By contrast, in the case of two new sectors, both an $L L$ pair and an $H L$ pair can masquerade as an $H H$ pair by charging price $p_{H H}^{1}$. When $q_{L}=0$, a firm in an $L L$ pair does not suffer from any negative feedback on its reputation while the total cost of an $L L$ pair is lower than that of an $H L$ pair. Therefore, preventing an $L L$ pair from masquerading as an $\mathrm{HH}$ pair is more difficult than preventing an $H L$ pair from masquerading as an $\mathrm{HH}$ pair, which implies that co-branding relaxes the condition to have a separating equilibrium.

\section{Applications}

\section{Movie Stars and Blockbusters in the Motion Picture Industry}

We apply our model to the role movie stars play in the motion picture industry. Motion pictures are an experience good whose quality can be only ascertained with consumption. The final product also requires many complementary inputs, most important of them are actors, directors, and scripts among other things. For an executive of a 
studio who has a project, it is essential to convince (i.e., signal) the quality of the project to outsider financiers and final consumers to get the necessary funding for the project and generate considerable grosses.

In addition, in the motion picture industry, it is a reasonable assumption that movie stars and top directors are much more recognizable to financiers and final consumers than other key complementary inputs such as scripts. Thus, the involvement of established movie stars in a movie project may be associated with the high quality of other key inputs, and thus overall quality of the movie. Ravid (1999), for instance, describes the institutional details of the motion picture industry in which star participation can signal superior information, that is, a star will commit to a project because he or she knows that it is of high quality. According to Ravid (1999), we can view that the commitment of move stars in an early stage of the project "signals the quality of the project to the studio or to outside financiers (p. 465)."

The empirical literature also corroborates the signaling hypothesis, suggesting that the participation of a movie superstar acts as a signal of the quality of the project. For instance, Albert (1998) finds that stars serve as a signal or "markers" of film types and the value of stars is partly due to their ability to signal the quality of films in a consistent and predictable way. ${ }^{14}$ In addition, Chisholm (2004) finds a strong support for the hypothesis that the presence of stars plays a valuable role for studio executives ex ante even though an established star does not ensure a successful film ex post, and hence her data are consistent with the signaling hypothesis.

\section{Multinationals and Outsourcing}

Co-branding can be also used for a strategy to penetrate foreign markets by multinationals. Abratt and Motlana's (2002) case studies of Danone, a French multinational of yogurt manufacturer, and McCain Foods, a Canadian frozen food multinational, document how these firms penetrated into the South African market by co-branding with "well-known" local brands, Clover SA and Irvin and Johnson, respectively. These case studies show how co-branding can be used in brand transitions. ${ }^{15}$ Our model may also

\footnotetext{
${ }^{14}$ According to Albert (1998), a superstar movie actor, "either through his talent, ability to choose, or ability to acquire investment, is a marker of many successful films (p. 255)."

${ }^{15}$ The example of Lenovo can be interpreted in a similar vein. When IBM sold its PC division to China-based Lenovo Group and take a minority stake, the deal allowed Lenovo to use IBM's logo for five years. After the sale, Lenovo marketed its PC with the brand name of "Lenovo IBM Thinkpad." The rationale behind the deal for Lenovo was believed to be that the co-branding arrangement helps Lenovo expand in the global market where it is relatively unknown.
} 
shed some light on the rising activities in outsourcing we observe recently. ${ }^{16}$ Nike, for instance, does most manufacturing activities through contractual arrangements with oversee factories whereas the design and marketing of its products is conducted in the United States. What distinguishes this kind of outsourcing activities from the purchase of any other foreign products by American consumers is the use of outsourcing firms' brand names. Perhaps foreign producers may have a hard time in penetrating the American market due to low recognition of their own brand names; American consumers may be reluctant to purchase foreign products with unknown brand names due to quality concerns. In contrast, they are willing to buy Nike products with a high price even though they are well aware that the actual manufacturing has been carried out by foreign manufacturers. They trust that Nike knows the capability of foreign manufacturers better than they do and the fact that Nike chose a particular foreign manufacturer certifies the capability of the foreign producer.

\section{Co-authorship with Established Scholars}

The same intuition can be applied to co-authorship decisions in the academic market. The currency in the academic market is recognition. Even though there is no monetary price attached to academic work, we can interpret the amount of attention readers pay to any particular work as its market price. When there are co-authors for a particular paper, the quality of the paper depends on the quality of contributions by all authors. When the quality of the paper is low, it may be difficult for outside readers to ascertain who is responsible for the quality. It is a reasonable assumption that potential collaborators know each other's ability compared to outsiders. It may be difficult for unknown young scholars to convince other academics to read their papers. In such a case, one effective way to signal their ability and build reputation may be to work with established scholars. Established scholars will be selective in choosing their co-authors as long as there is residual uncertainty about senior scholar's ability as assumed in our model. As a result, co-authorship with established scholars can be used to signal young scholar's ability even when it would be difficult to do on their own with single authorship. The following remark from a Nobel laureate illustrates well our point:

"... it clearly did my student... no harm at all to have me as a second author of the paper. It called people's attention to the paper who might otherwise not [have] read it at all... Nor as a matter of fact, did it do me any harm, even if I was heavily responsible for it, to have him as co-author." (Zuckerman, 1967, p.396)

\footnotetext{
${ }^{16}$ See Feenstra (1998).
} 


\section{Concluding Remarks}

In this paper, we have developed a theory of reputation leverage in which the reputation of an established firm is used to help an unknown firm establish its own reputation through co-branding. The marketing literature points out an increasing popularity of co-branding in the introduction of new consumer products in recent years and posits that the practice plays a key role in changing consumers' perception that the two constituent products will be regarded as being similar quality. Our model provides a micro-foundation of the mechanism through which such a linkage in consumers' perception takes place and identifies conditions under which co-branding is a superior signaling device of product quality compared to pricing.

We believe that a similar leverage mechanism can be applied to a wide range of contexts that entail alliances of multiple parties, as we discussed in the previous section. Our theory also suggests that in the formation of strategic alliances reputation can constitute a key complementary asset that an established agent can bring to the table. We intend to extend our framework to explain various types of partnerships and hope that our theory shed light on the role of reputation in the formation of such alliances.

In particular, our perspective is useful to understand the role that brands of multinational firms play in the era of globalization. As the examples of our previous section illustrate, we can distinguish two types of leverage when reputation leverage occurs through co-branding between a global brand and a local one. Either the co-branding leverages the latter's reputation to the former (if the local brand enjoys high recognition and the global brand is relatively unknown in the local context) and thereby helps the former to penetrate local markets or it leverages the latter's reputation to the former. Through the second type of leverage, globalization can bring important benefit to a local economy which is poor in reputation capital. However, a multinational would be reluctant to leverage its reputation to a local firm if it has an ambition to be a global player; in this case, it might prefer outsourcing to co-branding. It would be interesting to study global brands' incentives to choose among different strategies in penetrating local markets.

\section{References}

Abratt, Russel and Patience Motlana (2002). "Managing Co-branding Strategies: Global Brands into Local Markets," Business Horizons: 43-50.

Albert, Steven (1998). "Movie Stars and the Distribution of Financially Successful Films in the Motion Picture Industry", Journal of Cultural Economics, 22(4): 249-70. 
Bagwell, Kyle and Robert W. Staiger (1989). "The Role of Export Subsidies When Product Quality Is Unknown", Journal of International Economics 27: 68-89.

Bar-Isaac, Heski (forthcoming). "Something to Prove: Reputation in Teams," Rand Journal of Economics.

Biglaiser, Gary(1993). "Middlemen as Experts," Rand Journal of Economics, 24: 212-223.

Cabral, Luis M. B. (2000). "Stretching Firm and Brand Reputation". Rand Journal of Economics, 31: 658-673

Chisholm, Darlene C. (2004). "Two-Part Share Contracts, Risk, and the Life Cycle of Stars: Some Empirical Results from Motion Picture Contracts", Journal of Cultural Economics, 28(1): 37-56

Cho, In-Koo and David Kreps (1987). "Signaling Games and Stable Equilibria", Quarterly Journal of Economics, 102: 179-221.

Choi, Jay Pil. (1998). "Brand Extension as Informational Leverage". Review of Economic Studies, 65: 655-69

Feenstra, Robert C. (1998), "Integration of Trade and Disintegration of Production in the Global Economy", Journal of Economic Perspectives 12 (4): 31-50.

Grossman, Sanford J. and Oliver Hart (1986). "The Costs and Benefits of Ownership: A Theory of Vertical and Lateral Integration," Journal of Political Economy 94(4): 691719.

Hart, Oliver and John Moore (1990). "Property Rights and the Nature of the Firm", Journal of Political Economy 98(6): 1119-1158.

Kremer, Michael (1993). "The O-Ring Theory of Economic Development", Quarterly Journal of Economics, 108(3): 551-75

Kreps, D. (1990). "Corporate Culture and Economic Theory." In J. Alt and K. Shepsle, eds., Perspectives on Positive Political Economy, New York: Cambridge University Press.

Levin, Jonathan and Steven Tadelis (2005). "Profit Sharing and The Role Of Professional Partnerships," Quarterly Journal of Economics, 120 (1): 131-171.

MacDonald, Glenn M. (1988). "The Economics of Rising Stars", American Economic Review, 78(1): 155-66

Rao, Akshay R, Lu Qu, and Robert W. Ruekert (1999), "Signaling Unobservable Product Quality through a Brand Ally," Journal of Marketing Research 34: 258-268.

Ravid, S. Abraham (1999). "Information, Blockbusters, and Stars: A Study of the Film Industry", Journal of Business, 72(4): 463-92 
Rosen, Sherwin (1981). "The Economics of Superstars", American Economic Review, 71(5): 845-58

Simonin, Bernard L. and Julie A. Ruth (1998). "Is a Company Known by the Company It Keeps? Assessing the Spillover Effects of Brand Alliances on Consumer Brand Attitudes," Journal of Marketing Research, 35: 30-42.

Tadelis, Steven. (1999). "What's in a Name? Reputation as a Tradable Asset". American Economic Review, 89: 548-563

Thal, Jeanine. (2007). "On the Signaling and Feedback Effects of Umbrella Branding." Working Paper, European University Institute.

Wallace, W. Timothy, Alan Seigerman and Morris B. Holbrook (1993). "The Role of Actors and Actresses in the Success of Films: How Much Is a Movie Star Worth?" Journal of Cultural Economics, 17(1):1-27

Washburn, Judith H., Brian D. Till, and Randi Priluck (2000). "Co-branding: Brand Equity and Trial Effects," Journal of Consumer Marketing, 17 (7): 591-604.

Zuckerman, Harriet (1967). "Nobel Laureates in Science: Patterns of Productivity, Collaboration, and Authorship," American Sociological Review, 32(3): 391-403. 